\title{
Development of High Ductility and Adequate Strength in Pure Titanium Recycled from Chips by Multi-Pass Equal Channel Angular Pressing
}

\author{
Peng Luo* \\ Institute of Materials for Clean Energy Manufacturing and Shanghai Collaborative Innovation Center for Heavy Casting/Forging \\ Manufacturing Technology, School of Materials, Shanghai Dianji University, Shanghai 201306, P.R. China
}

Pure titanium chips were consolidated by a solid-state recycling process in the form of multi-pass equal channel angular pressing (ECAP) with the number of passes up to 16 passes. Electron backscatter diffraction reveals that low angle grain boundaries (with misorientation $<15^{\circ}$ ) were substantially presented within coarse grains which were enclosed by high angle grain boundaries $\left(\geq 15^{\circ}\right)$. Adequate yield strength (above $300 \mathrm{MPa}$ ) was achieved. It was contributed not only by high angle grain boundary, but also low angle grain boundary. At the same time, high ductility (with a uniform elongation up to 27\%) is derived from the strain hardening owing to the existence of low angle grain boundaries and coarse grains. The mechanical properties of the recycled titanium are good enough to compare with those of the reference ingot subjected to the multi-pass ECAP. [doi:10.2320/matertrans.M2017235]

(Received July 24, 2017; Accepted October 12, 2017; Published November 17, 2017)

Keywords: $\quad$ titanium, strength, ductility, severe plastic deformation

\section{Introduction}

Due to satisfactory strength and excellent biocompatibility and corrosion resistance, pure titanium is extensively used in biomedical and chemical engineering ${ }^{1)}$. To fabricate complex components of titanium, high-precision machining is widely conducted. A significant proportion of work-piece will be lost to valueless chips. To reduce waste re-melting and casting is applied at the cost of energy consumption. A solid-state recycling is in urgent need. To date, several kinds of easily deformed metals, e.g., aluminum or magnesium alloy, and pure iron, have been successfully recycled in the solid-state way $^{2-5)}$. Nevertheless, for titanium, the difficulty in exploring its solid-state recycling is primarily caused by the poor deformability considering a hexagonal closepacked structure. Efforts have been paid on the recycling of titanium wastes by avoiding re-melting, for example, Luo et $a l .{ }^{6)}$ investigated the recycling of titanium wastes by severe plastic deformation, and achieved a uniform elongation about $13 \%$. Moreover, combining annealing with the solid-state consolidation, Ti-6Al-4V alloy was recycled with a uniform elongation about $15 \%{ }^{7)}$. However, a cost-effective recycling is hard to be realized with the application of costly heat treatment. Hydrogenation was used by Jang et al. ${ }^{8,9)}$ to convert chips of titanium to $\mathrm{TiH}_{2}$, subsequently pulverized to metastable powders. Fully dense bulk titanium was finally consolidated by hot-press sintering at $750^{\circ} \mathrm{C}$, during which metastable $\mathrm{TiH}_{2}$ powders were decomposed into titanium and $\mathrm{H}_{2}$ (i.e., dehydrogenation). Extremely high yield strength above $1.5 \mathrm{GPa}$ was endowed to as-recycled $\alpha$-titanium because of ultrafine grain sizes and highly concentrated interstitials such as hydrogen atoms. Unfortunately, suffering from serious impurity defects the recycled sample fails to exhibit ductility. A primary task one should take is to develop excellent tensile ductility for titanium recycled after the solid-state process.

It can be a beneficial way to innovate by introducing se-

*Corresponding author, E-mail: luopeng@sdju.edu.cn vere plastic deformation. As a typical severe plastic deformation that imposes intense strain to metals, equal channel angular pressing (ECAP) has been used to refine the grains of titanium ingot ${ }^{10,11)}$. The temperature of ECAP is about $600^{\circ} \mathrm{C}$ for titanium. This temperature is reasonably favorable because it is prominently lower than that adopted by powder metallurgy such as spark plasma sintering (at $\left.850^{\circ} \mathrm{C}\right)^{12)}$. It is speculated that the recycling value of titanium wastage would be improved with the application of ECAP.

As reported in the present paper, it is meaningful to achieve tensile ductility in the hard-to-deform metals such as titanium, as recycled in a solid-state way when realizing the difficulty with which it is deformed. Obviously, to obtain pronounced ductility, the contact between chips is required to be severely disrupted by intense shear strain as induced by ECAP. Surface oxides were then ruptured to expose fresh matrices. In our practice, the consolidation proceeded very smoothly at $590^{\circ} \mathrm{C}$ after a multiple number of passes up to 16 , and sufficient thermo-mechanical welding was achieved between titanium matrices by imposing collaboratively a forward pressure as high as $\sim 1.0 \mathrm{GPa}$ and a back-pressure $\sim 200 \mathrm{MPa}$. The present paper is a study demonstrating that ECAP is effective to develop a solid-state recycling by high pressure (up to $\sim 1.0 \mathrm{GPa}$ ) at elevated temperature.

On the other hand, to understand microstructure and mechanical properties is of significance to design materials of high performance. Grain refinement is effective to improve yield strength but impairs ductility. The reason as to why both are paradoxical is the lack of strain hardening within fine grains. In this study, adequate yield strength (above $300 \mathrm{MPa}$ ) and high ductility (with a uniform elongation $\sim 27 \%$ ) were achieved in pure titanium recycled from chips by ECAP. As revealed by electron backscatter diffraction, low-angle grain boundaries (with misorientation $<15^{\circ}$ ) were substantially presented within coarse grains surrounded by high-angle grain boundaries $\left(\geq 15^{\circ}\right)$. To analyze the roles played by both kinds of boundaries in developing strength and ductility is a work that deserves to be undertaken. 


\section{Experimental Procedure}

A workpiece of commercially pure titanium (ASTM Grade 2) was machined by face mill. Being averagely $4.7 \times$ $3.7 \times 0.1 \mathrm{~mm}$, chips of thin flakes were produced by cuts in small axial depth. Additional ultrasonic cleaning with ethanol $(99.9 \%)$ was carried out prior to recycling. ECAP consolidation was conducted using a die with two equal channels in diameter $(\sim 11 \mathrm{~mm})$ intersecting at $90^{\circ}$. The pile of chips were wrapped with a piece of steel foil, and then with a piece of graphite paper (as solid lubricant). Before the die was heated, the chips wrapped were put in the entrance channel for cold consolidation, during which a forward plunger and backward one imparted a forward (pressing) pressure $\sim 0.6 \mathrm{GPa}$ and a back-pressure $\sim 50 \mathrm{MPa}$, respectively. Intimate contacts were developed between chips by doing the cold consolidation. A heating device enabling stabilization of temperature within $\pm 1^{\circ} \mathrm{C}$ was designed to heat the die to $590^{\circ} \mathrm{C}$. The forward plunger moving at $\sim 5 \mathrm{~mm} /$ min imposed on the chips a pressure up to $\sim 1.0 \mathrm{GPa}$. At the same time, the backward plunger provided a back-pressure up to $\sim 200 \mathrm{MPa}$. Multiple numbers of passes up to 16 were designed to sufficiently consolidate chips. The ECAP consolidation was conducted following route $\mathrm{C}$, i.e., $180^{\circ}$ rotations clockwise about the sample's longitudinal axis (with respect to the pressing direction) between consecutive passes. It is demonstrated that route $\mathrm{C}$ is effective to refine grains within limited numbers of passes, and has been widely adopted although there are other routes proved to be efficient, e.g., route $\mathrm{Bc}^{13)}$. Moreover, the consolidation is a continuous process since as controlled by hydraulic switch valves, either plungers acted alternatively as a forward (pressing) or backward (back pressure) one. Therefore, desired numbers of passes were automatically accumulated without taking the sample out between passes. After the consolidation the sample was quenched immediately thereafter with cold water to maintain the microstructure formed at high temperature. Based on the Archimedes' principle, a Mettler Toledo 33360 density determination kit was used to confirm that full density $\left(4.51 \mathrm{~g} \mathrm{~cm}^{-3}\right)$ was readily obtained in all samples. Further, they were entirely inspected by scanning electron microscopy, to confirm the absence of any visible porosity. The sample for metallographic characterization was cut along cross and longitudinal section, respectively, then ground using $\mathrm{SiC}$ abrasive grinding papers with P-Grades up to 2500 . Polishing of the sample was conducted in a colloidal silica suspension using a vibratory polisher VibroMet Buehler at 220 VAC $50 \mathrm{~Hz}$. Electron backscatter diffraction was conducted in an FEI NOVA NanoSEM 230 using the AZTec HKL Max acquisition system. The diffracting results were analyzed by HKL Channel 5 TANGO. In addition, to compare the effect of grain refinement, extruded annealed ASTM grade 2 ingots (Tico Titanium Inc., USA) were adopted as the reference material in this work. Optical microscopy was used to measure the original average grain size of the as-received ingot, being $\sim 20 \mu \mathrm{m}$ prior to ECAP. To conduct this, the sample of the ingot was mechanically ground using $\mathrm{SiC}$ abrasive grinding papers with P-Grade up to 4000, then manually polished with Struers OP-S colloidal silica suspension $(\sim 0.1 \mu \mathrm{m})$, and finally etched in a solution of $\mathrm{H}_{2} \mathrm{O}(100 \mathrm{ml})$, $\mathrm{HF}(3 \mathrm{ml})$ and $\mathrm{HNO}_{3}(5 \mathrm{ml})$. To determine yield strength and ductility, at an initial strain rate of $\sim 1 \times 10^{-3} \mathrm{~s}^{-1}$, tensile testing was conducted using flat dog-bone samples (with a gauge length of $10 \mathrm{~mm}$ ) in the form of plates, whose rectangular cross sections have averagely the sizes $6 \times 2 \mathrm{~mm}$. on the MTS-810 material testing system equipped with a standard non-contacting laser extensometer (MTS-LX500). As shown in Table 1, the chemical compositions of the recycled titanium and reference ingot were analyzed by inductively coupled plasma atomic emission spectroscopy (ICP-AES).

\section{Results and Discussion}

A serrate profile has been clearly revealed for as-received chips by optical inspection (see Fig. 1). Undoubtedly, the surface area of chip would be underestimated by simply supposing a cubic model. However, only the greatest thickness was measured by a micrometer, which can effectively compensate the underestimate. To be exact, a number of the chips were picked randomly to measure their mass, $m$, and geometric dimensions such as the length $(l)$, width $(w)$, and thickness $(t)$. The surface area per unit weight of the chip, $S_{\mathrm{w}}$, is a key parameter to evaluate the consolidating effect. This parameter is defined as

$$
S_{\mathrm{w}}=\frac{A}{m}
$$

where $A$ is the surface area estimated by assuming a cubic model, as follows:

$$
A=2 \times(l \times w+l \times t+w \times t)
$$

The quality of consolidation is significantly influenced by chip surface area per unit weight $\left(S_{\mathrm{w}}\right)$, the statistical histogram of which is presented in Fig. 2. The distribution range of $S_{\mathrm{w}}$ is $40-70 \mathrm{~cm}^{2} \mathrm{~g}^{-1}$. In contrast, the value of $S_{\mathrm{w}}$ is increased to $10^{6}-10^{7} \mathrm{~cm}^{2} \mathrm{~g}^{-1}$ for nano- or micro-powders ${ }^{14)}$.

Table 1 Chemical composition of the recycled titanium and the reference ingot.

\begin{tabular}{cccccc}
\hline Sample & $\mathrm{Ti}$ & $\mathrm{O}(\mathrm{mass} \%)$ & $\mathrm{N}(\operatorname{mass} \%)$ & $\mathrm{C}(\operatorname{mass} \%)$ & $\mathrm{Fe}(\operatorname{mass} \%)$ \\
\hline Chip recycled & $\mathrm{Bal}$ & 0.18 & 0.12 & 0.005 & 0.16 \\
\hline Ti ingot & $\mathrm{Bal}$ & 0.17 & 0.01 & 0.01 & 0.09 \\
\hline
\end{tabular}

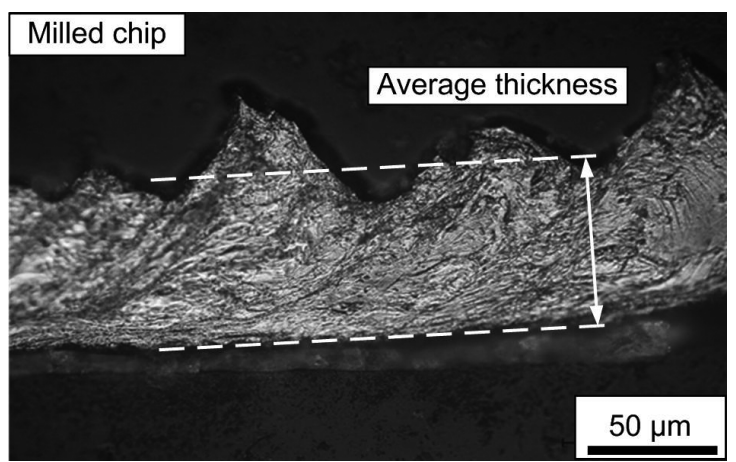

Fig. 1 Optical micrograph revealing a serrate profile of milled chip. 


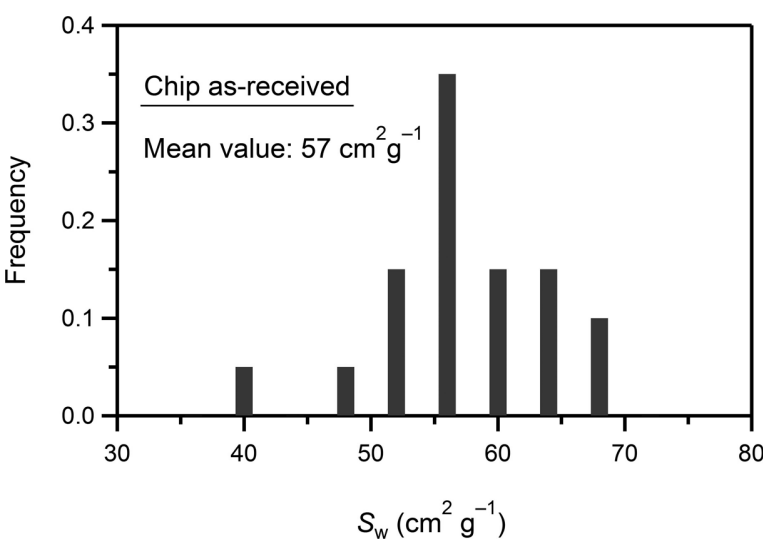

Fig. 2 Distribution of surface area per unit weight $\left(S_{\mathrm{W}}\right)$ of as-received chips.

Therefore, it is extremely difficult to consolidate ultrafine powders because the work required for porosity closure is increased at large $S_{\mathrm{w}}$. Therefore, chips are more favorably consolidated, and the smaller the value of $S_{\mathrm{w}}$, the better the recycling quality would be.

Despite the geometrical restriction by a large value of $S_{\mathrm{w}}$ in powder system, ECAP has exhibited promising potential in consolidating titanium alloy powders by significantly lowering the processing temperature ${ }^{15)}$, which is very favorable to the processing of titanium (and alloys) because ECAP temperature is prominently lower than that $\left(600-1000^{\circ} \mathrm{C}\right)$ of the conventional powder metallurgy (e.g., sintering) and ingot metallurgy (e.g., forging and/or extrusion). However, to achieve satisfactory ductility is a challenging topic for the solid-state recycled titanium because it is lack of deformability due to a hexagonal close-packed crystal structure. In the present study, ECAP could proceed very smoothly and ductility of the recycled pure titanium was significantly enhanced while chips were consolidated with a configuration of ECAP parameters, i.e., a large back-pressure 200 MPa, a multiple number of passes up to 16 , and elevated deformation temperature at $590^{\circ} \mathrm{C}$. The achievement of full density and high ductility can be attributed to a couple of factors. One is the contribution by mechanical welding (caused by severe plastic deformation of ECAP under a large back-pressure). The other is the contribution by atomic diffusion nearby chip boundaries. Both play a very beneficial role in developing strong bonding between chips after multi-pass ECAP. It is because of the two mechanisms that ECAP is purely a solid-state consolidating process. Obviously, A multiple number of passes and large value of back-pressure are indispensable for good equilibrium between strength and ductility.

Successful consolidation gave a favorable base for characterizing microstructure and mechanical properties. By resolving high angle grain boundaries into black lines and low angle grain boundaries into white ones, microstructures of the recycled chips and reference titanium ingot (subjected to ECAP) are presented in Fig. 3 on cross and longitudinal section, respectively. It is observed that low angle grain boundaries exist substantially after ECAP. They may result from the dynamic recovery taking place more easily in titanium owing to high stacking fault energy ${ }^{16)}$. The main reason at- tributed to this might be related to the viewpoint that dynamic recovery is responsible for the formation of substructure, the primary component of which would be the network of low angle grain boundaries especially after a heavy plastic deformation ${ }^{16)}$. Moreover, owing to severe strain imposed to samples, there appeared a lot of fine to medium-sized grains (i.e., $5-10 \mu \mathrm{m}$ ). It is clearly revealed that grain morphology is liable to be equiaxed on cross section of the sample, while more likely to be elongated along the longitudinal section. This microstructure feature is consistent with the one of pure aluminum subjected to ECAP, as reported elsewhere $^{17)}$

Parametric statistics was carried out giving three groups of key microstructure characteristics used for analyzing the effect of microstructure on mechanical properties. They are about circle equivalent diameter of the grain bound by high angle grain boundaries (Fig. 4), linear intercept between low angle grain boundaries (Fig. 5), and misorientation angle of grain boundaries (Fig. 6). According to Humphreys ${ }^{18)}$, electron backscatter diffraction is good at determining grain size defined as circle equivalent diameter. To conduct this, grains were reconstructed by electron backscatter diffraction. Then, the size of a grain was determined from the number of data points or pixels within it. By giving a pixel step size, grain area was calculated. Consequently, circle equivalent diameter is determined as the diameter of a circle having the same area as that of the true grain. The histograms confirm the characteristics revealed by electron backscatter diffraction image (see Fig. 3). For example, narrower distribution of circle equivalent diameter on the cross section implies an improved homogeneity of microstructure on the cross section of the sample. Meanwhile, the histograms indicate that mean grain size on longitudinal section is slightly larger than that on cross section because of the formation of more elongated grains (instead of fragmented ones) along the longitudinal plane. Distributions of boundary misorientations indicate that a significant fraction is low angle grain boundary in all cases. This phenomenon provides supporting information to the occurrence of recovery resulting in more substructure (e.g., low angle boundary). The statistical averages of these parameters are summarized in Table 2. In addition, tensile true stress vs. true strain curves of the consolidated chips and reference ingot are depicted in Fig. 7, indicating an excellent ductility that has been achieved in the recycled titanium.

The underlying mechanism behind structure-property relation was manifested on account of different types of microstructure characteristics. The yield strength $\left(\sigma_{\mathrm{y}}\right)$ is primarily derived from lattice friction stress, grain boundaries, interstitials (e.g., oxygen, nitrogen, and carbon), respectively, i.e.:

$$
\sigma_{\mathrm{y}}=\sigma_{0}+\sigma_{\mathrm{LAGB}}+\sigma_{\mathrm{HAGB}}
$$

where $\sigma_{0}$ represents lattice friction, and is approximately equal to interstitial contribution $\left(\Delta \sigma_{\mathrm{ss}}\right)$, i.e., $\sigma_{0}=\Delta \sigma_{\mathrm{ss}}=$ $0.02 G c_{\mathrm{ss}}^{1 / 219)}$, where $c_{\mathrm{ss}}$ is the oxygen equivalent (in atom\%, shown in Table 2) that was converted from $O+20 \mathrm{~N}+\frac{3}{4} \mathrm{C}$ (analyzed by ICP-AES), and $G$ is the shear modulus $\left(=45.6 \mathrm{GPa}\right.$ for titanium). $\sigma_{\mathrm{HAGB}}$ and $\sigma_{\mathrm{LAGB}}$ is the contribution by high angle grain boundaries and low angle grain 

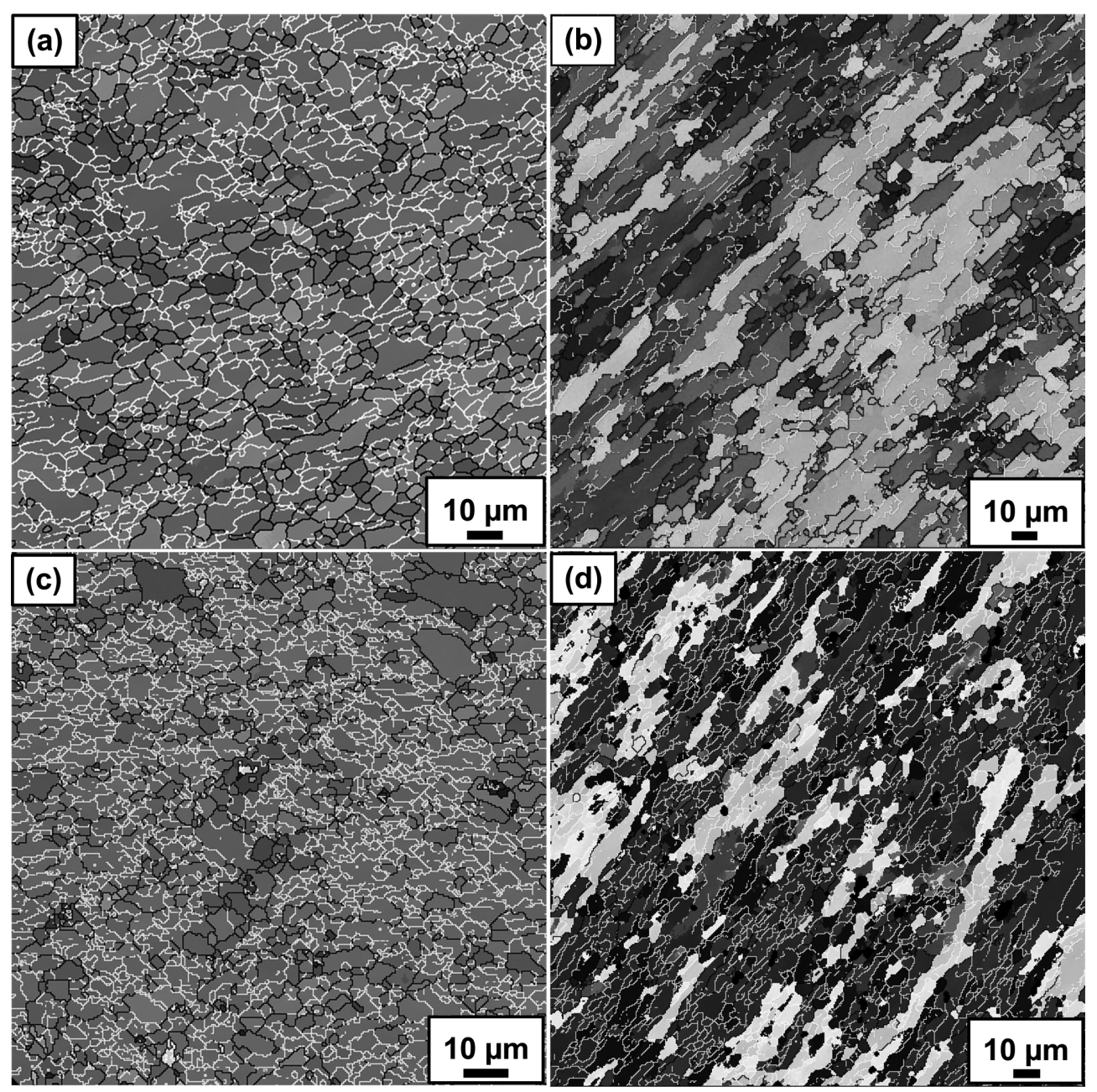

Fig. 3 Microstructure of recycled titanium on (a) cross and (b) longitudinal section, and reference ingot on (a) cross and (b) longitudinal section respectively, exhibiting grains bound by high angle grain boundaries (with black lines) and an abundance of low angle grain boundaries (with white lines).

boundaries, respectively. $\sigma_{\text {LAGB }}$ is given by the Taylor equation $\sigma=M \alpha G b \rho^{1 / 2}$, where $M(\sim 3)$ is the Taylor factor, $\alpha$ $(=0.2)$ is a constant, $b$ is the Burgers vector length ( $0.347 \mathrm{~nm}$ for titanium), and $\rho$ is the dislocation density estimated by $\rho=\frac{\left.3 \bar{\theta}_{\mathrm{LAGB}} 20,21\right)}{L b}$, where $\bar{\theta}_{\mathrm{LAGB}}$ is the average misorientation of low angle grain boundaries (calculated from Fig. 6, and listed in Table 2), and $L$ is mean linear intercept between low angle grain boundaries (determined from Fig. 5). As a result, one arrives at

$$
\sigma_{\mathrm{LAGB}}=M \alpha G \sqrt{3 b \bar{\theta}_{\mathrm{LAGB}}} L^{-1 / 2}
$$

The contribution of high angle grain boundaries can be evaluated by the Hall-Petch equation, i.e.:

$$
\sigma_{\mathrm{HAGB}}=k_{\mathrm{y}} d^{-1 / 2}
$$

where $d$ is the average circle equivalent diameter of grains bound by high angle grain boundaries (determined from Fig. 4), and $k_{\mathrm{y}}$ is the Hall-Petch slope (0.3-0.4 $\mathrm{MPa} \mathrm{m}^{1 / 2}$ for titanium) $)^{22,23)}$.

As shown in Fig. 8, the theoretical estimate of $\sigma_{\mathrm{y}}$ agrees remarkably with the experimental $0.2 \%$ proof stress $\left(\sigma_{0.2}\right)$. The yield strength of as-recycled titanium is comparable to that of reference ingot, which demonstrates the effectiveness of ECAP for improving the quality of recycled wastes by the avoidance of re-melting.

In this study, high ductility, i.e., a noticeable uniform elongation $\left(\varepsilon_{\mathrm{u}}\right.$, prior to the occurrence of necking) $\sim 27 \%$ was achieved in the recycled chips after 16 passes. The development of ductility is primarily due to a stabilizing mechanism, which is capable of postponing the occurrence of necking and overcoming plastic instability ${ }^{24)}$. The formation of coarse grains (e.g., with an average size $\geq 5 \mu \mathrm{m}$ ) allows strong capacity of dislocation storage in order to accommodate considerable strain hardening to depress the necking. Moreover, an abundance of low angle grain boundaries had been produced. The extensive distribution of them promotes the strain hardening as observed in the tensile true stress $(\sigma)$ vs. true strain $(\varepsilon)$ curves (as shown in Fig. 7). The strain hardening rate after yielding is defined as ${ }^{25}$ )

$$
\Theta=\frac{1}{\sigma}\left(\frac{\partial \sigma}{\partial \varepsilon}\right)_{\dot{\varepsilon}}
$$

where $\dot{\varepsilon}\left(=10^{-3} \mathrm{~s}^{-1}\right)$ is the strain rate at which tensile testing was conducted. The relation $\Theta$ vs. $\varepsilon$ is depicted in Fig. 9 for the recycled chips and reference ingot. It is indicated that ductility is positively related to $\Theta$. For example, $\varepsilon_{\mathrm{u}}$ reaches $\sim 33 \%$ for reference ingot, and an inferior level of ductility $\left(\varepsilon_{\mathrm{u}} \sim 27 \%\right)$ was assigned to the recycled titanium. Correspondingly, the value of $\Theta$ is smaller, and drops more 

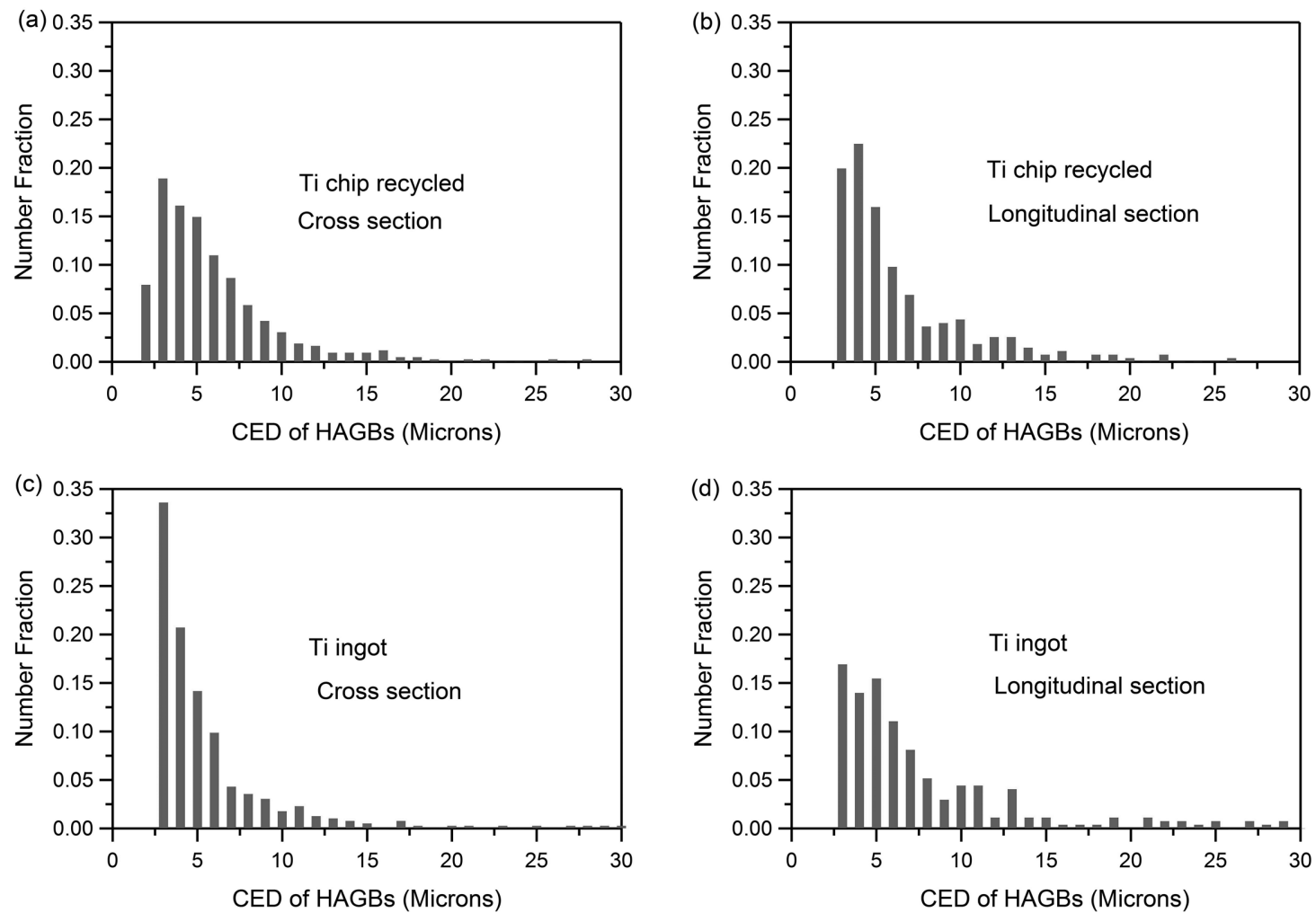

Fig. 4 The distribution of circle equivalent diameter (CED) of grains bound by high angle grain boundaries (HAGBs): the recycled titanium on (a) cross and (b) longitudinal section, and reference ingot on (c) cross and (d) longitudinal section, respectively.
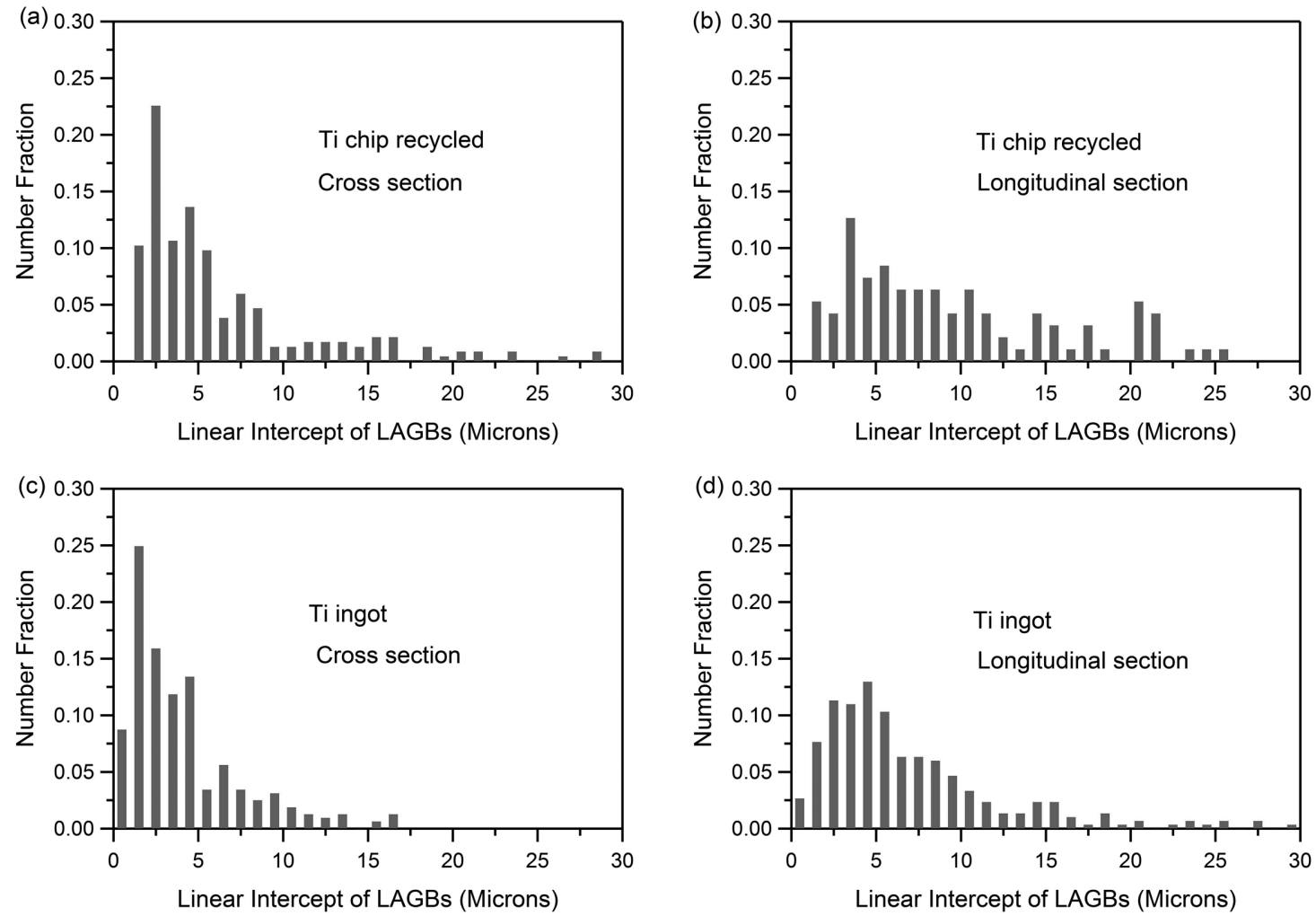

Fig. 5 The distribution of linear intercept between low angle grain boundaries (LAGBs): the recycled titanium on (a) cross and (b) longitudinal section, and reference ingot on (c) cross and (d) longitudinal section, respectively. 

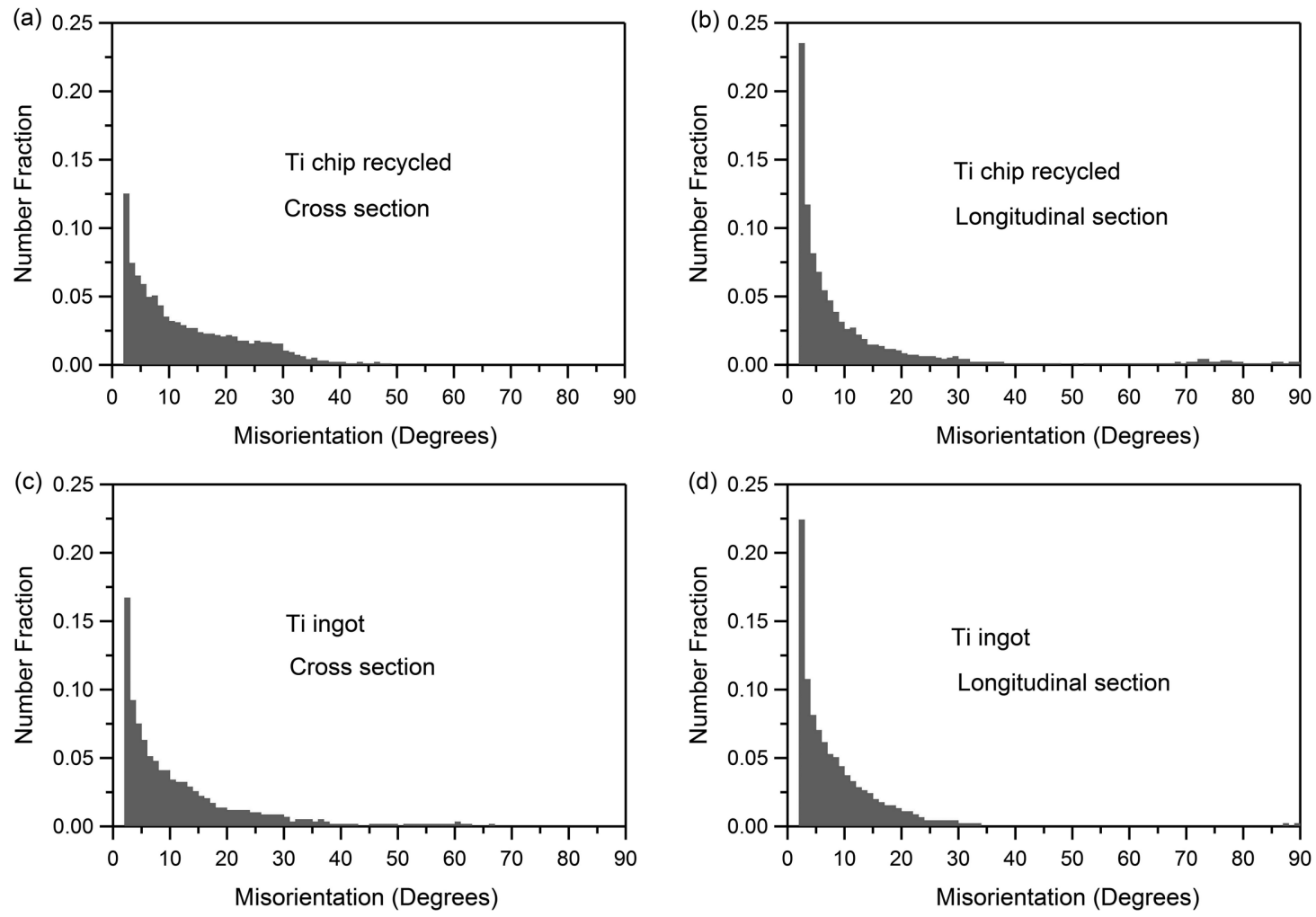

Fig. 6 The distribution of misorientation: the recycled titanium on (a) cross and (b) longitudinal section, and reference ingot on (c) cross and (d) longitudinal section, respectively.

Table 2 Microstructure and mechanical properties, i.e., the average grain size $(d)$, mean linear intercept $(L)$ and misorientation $\left(\bar{\theta}_{\mathrm{LAGB}}\right)$ between low angle grain boundaries, the oxygen equivalent $\left(c_{\mathrm{ss}}\right), 0.2 \%$ proof stress $\left(\sigma_{0.2}\right)$, and the uniform elongation $\left(\varepsilon_{\mathrm{u}}\right)$ of the recycled chips and reference ingot.

\begin{tabular}{|c|c|c|c|c|c|c|}
\hline Sample & $d(\mu \mathrm{m})$ & $L(\mu \mathrm{m})$ & $\bar{\theta}_{\text {LAGB }}\left({ }^{\circ}\right)$ & $c_{\mathrm{ss}}($ atom $\%)$ & $\sigma_{0.2}(\mathrm{MPa})$ & $\varepsilon_{\mathrm{u}}(\%)$ \\
\hline Chip recycled & $6.15 \pm 0.25$ & $7.9 \pm 1.6$ & 4.4 & 1.911 & $320 \pm 20$ & 27 \\
\hline Ti ingot & $6.45 \pm 1.35$ & $5.7 \pm 1.6$ & 6.3 & 1.216 & $340 \pm 10$ & 33 \\
\hline
\end{tabular}

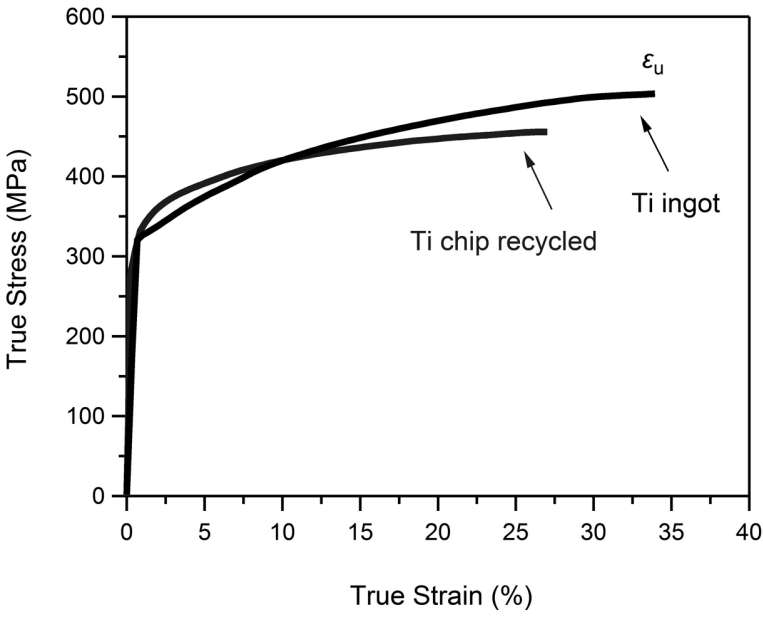

Fig. 7 Tensile true stress vs. true strain curves of the recycled titanium and reference ingot, exhibiting a noticeable uniform elongation $\left(\varepsilon_{\mathrm{u}}\right)$.

quickly with $\varepsilon$ in the recycled titanium. Moreover, for a tensile curve presented with true stress and strain, it is inappropriate to depict a descending trend since the necking point $^{24)}$. Instead, to depict a tensile tendency up to the ulti-

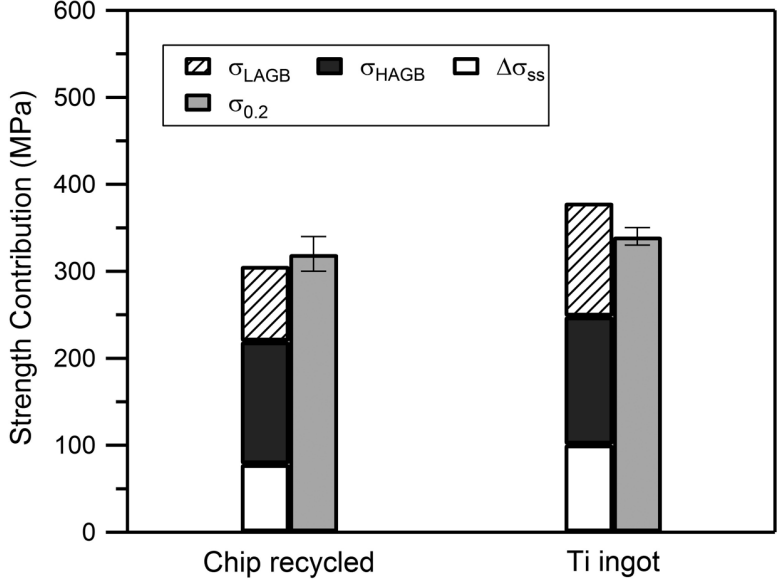

Fig. 8 Theoretical evaluation of strength contributions by interstitials $\left(\Delta \sigma_{\mathrm{ss}}\right)$, high angle grain boundaries $\left(\sigma_{\mathrm{HAGB}}\right)$, and low angle grain boundaries $\left(\sigma_{\text {LAGB }}\right)$, and the comparison between the theoretical estimate and experimental $0.2 \%$ proof stress $\left(\sigma_{0.2}\right)$.

mate fracture (i.e., not only the ascending curve defining a uniform elongation, but also the descending one resulting in fracture), one can use engineering stress and strain. 


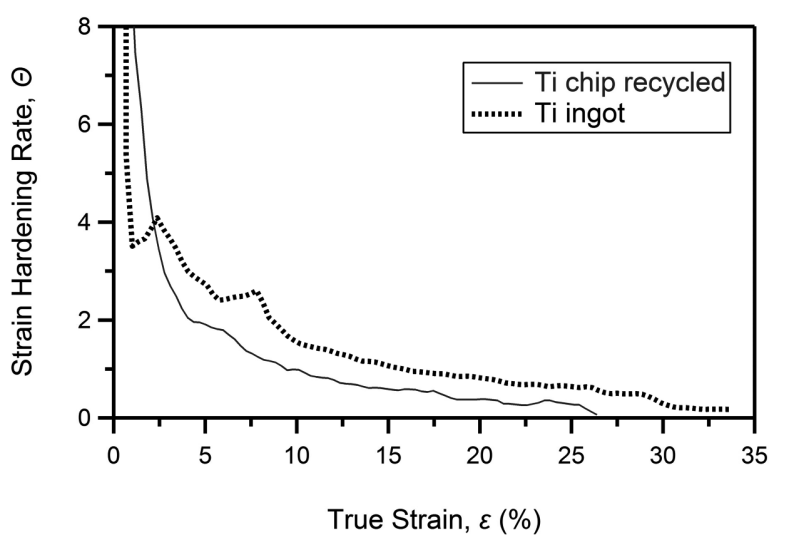

Fig. 9 The variation of strain hardening rate $(\Theta)$ with true strain $(\varepsilon)$.

Nevertheless, it is more convenient to use true stress and strain in revealing the underlying principle to develop high ductility and adequate strength.

It is well accepted that in the mode of ductile fracture, the ultimate failure is caused by the coalescence between sites of micro-crack nucleation, as described by a modified Griffith criterion ${ }^{26)}$ :

$$
\sigma=0.798\left(\frac{E \gamma}{a}\right)^{1 / 2}
$$

where $E$ is the Young's modulus (100-145 GPa for titanium), $\gamma$ is the specific deformation energy positively related to the ductility, and $a$ is a geometric parameter measuring the scale of micro-cracks. According to the modified Griffith criterion, for certain value of $\sigma$, an inferior grade of $\gamma$ (i.e., the degradation of ductility) results from the existence of defects (implying an increment of $a$ ). In the present study, owing to a large back-pressure $\sim 200 \mathrm{MPa}$ and high consolidation temperature at $590^{\circ} \mathrm{C}$, strong interfaces between chips were produced to reduce the possibility of crack nucleation at interfaces.

As pointed out by Morris et l. $^{27)}$, low angle grain boundaries with misorientation angles of a few degrees would become strong enough as commonly recognized grain boundaries. Therefore, substantial presence of low angle grain boundaries, as observed in this work, could inhibit the propagation of cracks, which is very beneficial to depressing the coalescence of micro-cracks that might lead to the ultimate failure. Consequently, good balance between $\gamma$ and $\sigma$ would be achieved with smaller value of $a$. This may imply an excellent ductility $\left(\varepsilon_{\mathrm{u}}=27 \%\right)$ with no excessive sacrifice of strength.

The failure behaviour of tensile samples was manifested by scanning electron microscopy fractography. The appearances of the fracture surfaces of the recycled chips and reference ingot are presented in Fig. 10. For the chips consolidated, the profile of fracture surface is characterized by the presence of shallow dimples (see Fig. 10(a)). From metallurgical viewpoint, high consolidation temperature and a multiple number of passes to 16 created a fracture surface free of visible porosity and impurities. By contrast, the fractograph of reference ingot indicates that its failure is typical of dimpled ductile fracture (Figs. 10(b)). Moreover, the heterogeneously distributed dimple size, as can be seen in the recy-
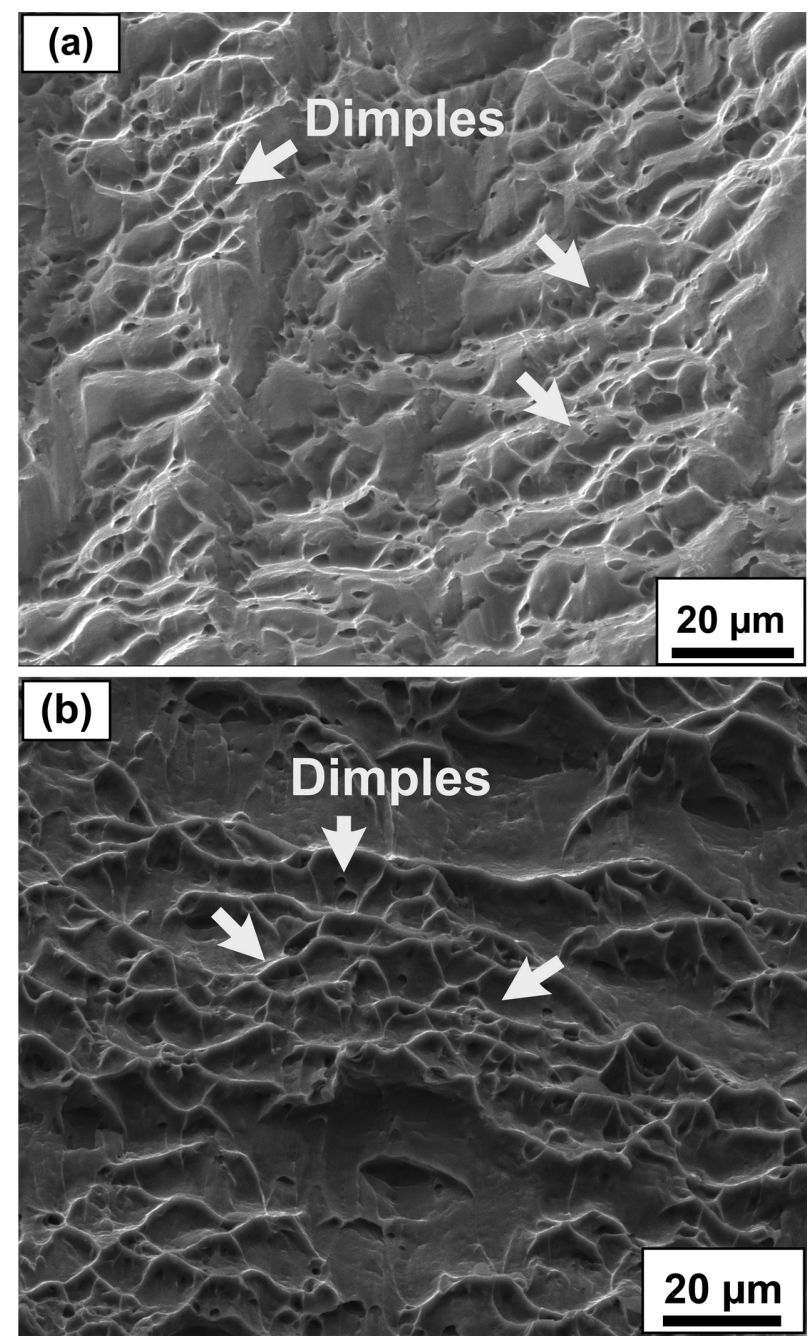

Fig. 10 Scanning electron microscopy fractography of the tensile sample of (a) the recycled titanium and (b) reference ingot, exhibiting a dimpled ductile fracture characteristic.

cled chips (Fig. 10(a)), takes negative effect on ductility. This heterogeneity may be derived from the non-uniformity of grain sizes, which is unfavourable to the coherency between grains once the sample was deformed. However, homogeneous distribution of dimple sizes is meaningful to obtaining better ductility in the reference ingot $\left(\varepsilon_{\mathrm{u}}=33 \%\right)$.

\section{Conclusions}

In summary, a success in the solid-state recycling of titanium chips was realized by equal channel angular pressing. Excellent consolidation quality is responsible for the attainment of satisfactory mechanical properties such as yield strength and ductility. A strengthening model was given to indicate that a significant contribution to yield strength is by not only high angle grain boundaries, but also low angle grain boundaries. The theoretical estimate of yield strength by the model is in agreement with the experimental $0.2 \%$ proof stress. Simultaneously, good equilibrium between ductility and yield strength is primarily attributed to microstructure characteristics involving coarse grains (to accommodate strain hardening) and low angle grain boundaries (to improve strain hardening, and impede the propagation of mi- 
cro-cracks). Excellent metallurgical quality of the recycled titanium ensures the closure of porosity and the absence of any visible impurities. Homogeneous distribution of dimple sizes on the fracture surface is very favourable to the ductility. The combination of high uniform elongation $\sim 27 \%$ and adequate yield strength $\sim 320 \mathrm{MPa}$ endows the recycled chips with considerable promise for potential applications.

\section{Acknowledgements}

This study was supported by the Defence Materials Technology Centre. The author gratefully acknowledges the financial support from Shanghai Collaborative Innovation Centre for Heavy Casting/Forging Manufacturing Technology. My thanks are due to Q.D. Hu at Shanghai Jiaotong University, and K. Xia with the University of Melbourne for assistance with sample preparation and electron backscatter diffraction.

\section{REFERENCES}

1) G. Lütjering and J.C. Williams: Titanium, (Springer, Berlin, 2003).

2) T. Aizawa, T. Luangvaranunt and K. Kondoh: Mater. Trans. 43 (2002) 315-321.

3) Y. Chino, T. Hoshika, J.S. Lee and M. Mabuchi: J. Mater. Res. 2 (2006) 754-760.

4) A.R. Anilchandra, R. Basu, I. Samajdar and M.K. Surappa: J. Mater. Res. 27 (2012) 709-719.

5) Y. Chino, H. Iwasaki and M. Mabuchi: J. Mater. Res. 19 (2004) 1524-1530.

6) P. Luo, D.T. McDonald, W. Xu, S. Palanisamy, M.S. Dargusch and K. Xia: Scr. Mater. 66 (2012) 785-788.

7) D.T. McDonald, E.W. Lui, S. Palanisamy, M.S. Dargusch and K. Xia:
Metall. Mater. Trans., A 45 (2014) 4089-4102.

8) J.M. Jang, W. Lee and S.H. Ko: Mater. Sci. Forum 534-536 (2007) $185-188$.

9) J.M. Jang, W. Lee, S.H. Ko and I.H. Kim: Adv. Mater. Res. 24-25 (2007) 171-174.

10) R.Z. Valiev, I.V. Alexandrov, Y.T. Zhu and T.C. Lowe: J. Mater. Res. 17 (2002) 5-8

11) Y.J. Chen, Y.J. Li, J.C. Walmsley, S. Dumoulin and H.J. Roven: Metall. Mater. Trans., A 41 (2010) 787-794.

12) Y. Long, H. Zhang, T. Wang, X. Huang, Y. Li, J. Wu and H. Chen: Mater. Sci. Eng. A 585 (2013) 408-414.

13) Y. Iwahashi, Z. Horita, M. Nemoto and T.G. Langdon: Acta Mater. 46 (1998) 3317-3331.

14) T. Peng, Q.D. Wang, Y.K. Han, J. Zheng and W. Guo: J. Alloy. Compd. 503 (2010) 253-259.

15) R. Lapovok, D. Tomus, and C. Bettles: Scripta Mater 58 (2008) 898-901.

16) F.J. Humphreys and M. Hatherly: Recrystallization and Related Annealing Phenomena, 2nd ed., (Elsevier, Oxford, 2004).

17) Y. Iwahashi, M. Furukawa, Z. Horita, M. Nemoto and T.G. Langdon: Metall. Mater. Trans., A 29 (1998) 2245-2252.

18) F.J. Humphreys: J. Mater. Sci. 36 (2001) 3833-3854.

19) K. Okazaki and H. Conrad: Acta Metall. 21 (1973) 1117-1129.

20) N. Hansen and X. Huang: Acta Mater. 46 (1998) 1827-1836.

21) D.A. Hughes and N. Hansen: Acta Mater. 48 (2000) 2985-3004.

22) M.A. Meyers and K.K. Chawla: Mechanical Behavior of Materials, 2nd ed., (Cambridge University Press, Cambridge, 2009).

23) T.H. Courtney: Mechanical Behavior of Materials, 2nd ed., (McGrawHill, Boston, 2000).

24) W.F. Hosford: Mechanical Behavior of Materials, (Cambridge University Press, Cambridge, 2005).

25) D. Jia, Y.M. Wang, K.T. Ramesh, E. Ma, Y.T. Zhu and R.Z. Valiev: Appl. Phys. Lett. 79 (2001) 611-613.

26) R.W. Hertzberg: Deformation and Fracture Mechanics of Engineering Materials, (John Wiley \& Sons, New York, 1976).

27) D.G. Morris, I. Gutierrez-Urrutia and M.A. Muñoz-Morris: J. Mater. Sci. 42 (2007) 1439-1443. 